\title{
VALORES DA PAISAGEM: OS SIGNIFICADOS DOS RIOS E MANGUEZAIS DA CIDADE DO RECIFE
}

\author{
VALUES LANDSCAPE: THE MEANING OF RIVERS AND THE MANGROVE RECIFE CITY
}

Onilda Gomes Bezerra*

Vera Lúcia Mayrinck de Oliveira Melo**

\begin{abstract}
RESUMO
Este trabalho apresenta uma reflexão acerca dos valores atribuídos à paisagem dos rios e manguezais da cidade do Recife, aqui representados pelo rio Capibaribe e pelo Manguezal do Pina, da interpretação dos significados evocados por grupos humanos que vivenciam e mantêm relação direta ou indiretamente com esses ambientes. Busca-se desenvolver subsídios para a construção de instrumentos de avaliação da conservação patrimonial como diretrizes norteadoras de políticas públicas de proteção do patrimônio natural e cultural. Parte-se do pressuposto que o meio ambiente é constituído por bens naturais e culturais, que se expressa na paisagem. Compreendendo que o sítio natural tem papel fundamental na formação fisiográfica, estruturação urbana e no uso e ocupação da cidade, constitui-se como marco patrimonial representativo da identidade sociocultural de sua paisagem. As paisagens podem ser interpretadas no tempo e no espaço de formas distintas, ao serem representadas segundo os valores atribuídos pelos olhares e pelas percepções, formados dentro de contextos socioeconômicos e culturais específicos. Na análise, adotou-se como fundamentação teórica a abordagem da paisagem cultural sob a ótica da Nova Geografia Cultural, e como resultados identificaram-se diferentes valores obtidos a partir da interpretação das representações dos grupos humanos investigados.

Palavras-chave: Paisagem. Valores da natureza. Patrimônio natural e cultural.
\end{abstract}

\begin{abstract}
This paper shows a reflection on the values assigned to the landscape of rivers and mangroves of the Recife's city, represented here by the Capibaribe river and Pina mangrove, through interpretation of the meanings evoked by human groups who live and maintain a relationship, directly or indirectly, with these environmental systems. The reflections seek to develop subsidies for the construction of instruments for assessment of heritage maintenance procedures or guidelines of public policies aimed at protecting the natural and cultural heritage. It starts with the assumption that the environment consists of natural and cultural assets, expressed
\end{abstract}

* Arquiteta e Urbanista, mestre em Geografia e doutora em Desenvolvimento Urbano pela Universidade Federal de Pernambuco (UFPE). Especialização em Gestão Ambiental pela Universitat Politècnica de València e em Desenvolvimento Urbano e Rural pela Universidade Católica de Pernambuco (UNICAP). Professora do Departamento de Arquitetura e Urbanismo da UFPE. Rua Ibiapaba, 90, ap. 1.102, Torre A, Tamarineira, 52051-100, Recife, PE, Brasil.

onibezerra@yahoo.com.br

** Arquiteta e Urbanista, mestre em Desenvolvimento Urbano pela Universidade Federal de Pernambuco (UFPE). Doutora em Geografia pela Universidade Federal do Rio de Janeiro (UFRJ). Pesquisadora do Conselho Nacional de Desenvolvimento Científico e Tecnológico (CNPq). Professora do Departamento de Arquitetura e Urbanismo da UFPE. Rua João Ramos, 285, ap. 501, 52011-080, Graças, Recife, PE, Brasil. veramayrinckmelo@gmail.com 
in the landscape. Understanding the natural site has a fundamental role in shaping physical, geographical, urban structure and the use and occupation of the city, constitutes a milestone asset representative of the cultural identity of its landscape. The landscapes can be interpreted in time and space in different ways to be represented according to the values assigned to them by the looks and perceptions formed within specific socioeconomic and cultural contexts. The analysis was adopted as the theoretical basis, the approach of the cultural landscape from the perspective of the New Cultural Geography, and as a result, we identified different values obtained from the representations interpreted by groups of people surveyed.

Keywords: Landscape. Values of nature. Natural and cultural heritage.

\section{INTRODUÇÃO}

A maioria das cidades se originaram e se desenvolveram próximas a mananciais hídricos, pois a água teve papel determinante na sobrevivência das aglomerações humanas, como também lugar de destaque na dinâmica da vida do homem e, consequentemente, no desenvolvimento técnico e material do espaço urbano. (SILVA, 1998; PONTES, 2003).

No Brasil, a relação estabelecida entre os rios e as cidades remonta à colonização, pois muitos núcleos coloniais se formaram às margens dos cursos d'água. Um desses importantes núcleos foi a cidade do Recife, capital do Estado de Pernambuco, localizada na região Nordeste do Brasil, cuja formação e expansão se deram sobre os rios e manguezais. Dentre eles, destacam-se o rio Capibaribe, que representa o sistema hídrico mais importante da cidade e, por outro lado, o Manguezal do Pina, com mais de 300 hectares de área, localizado na zona sul do Recife, sendo o maior remanescente de vegetação de mangue em área contínua ainda existente no sítio urbano.

Esses elementos naturais, além da grande importância do ponto de vista ambiental e ecológico, evidenciam-se como marcos culturais da paisagem urbana do Recife e se constituem como um bem patrimonial para a cidade, segundo o pressuposto teórico aqui adotado.

Ao longo do processo de urbanização da cidade, a relação dos moradores locais com esses recursos naturais se rompeu, dada à deterioração paulatina da ação antrópica promovida pelos despejos de esgotos domésticos e lixo, além dos aterros constantes. A degradação ambiental do rio Capibaribe e do Manguezal do Pina, consequência da polvição, se expressa visualmente na paisagem, podendo ser compreendida considerando as atitudes humanas em relação aos elementos da natureza a partir dos valores que lhes são atribuídos.

A relação homem/natureza, no mundo ocidental, durante milênios foi de dominação, sendo que o predomínio humano marcou esta relação. Por esse prisma, pressupõe-se que a natureza representa uma fonte de recursos ilimitados à disposição do homem. Com isso corrobora Santos (1992, p. 96-97) ao afirmar:

[...] a história do homem sobre a Terra é a história de uma ruptura progressiva entre o homem e o entorno. Esse processo se acelera quando, praticamente ao mesmo tempo, o homem se descobre como indivíduo e inicia a mecanização do planeta, armando-se de novos instrumentos para tentar dominá-lo. 
As paisagens do rio Capibaribe e do manguezal do Pina adquiriram, ao longo do tempo, significados específicos, como um produto social, modeladas pelas várias ações intencionais do homem, pautadas em valores e interesses distintos. Segundo Cosgrove (1998, p. 92): "[...] a paisagem é uma associação de formas resultante da expressão de várias manifestações culturais existentes na cidade ao longo do tempo, determinada e determinante da consciência e das práticas humanas".

O valor, neste trabalho, é entendido como atributo da paisagem analisada, reconhecido por um determinado grupo social, e não como característica inerente à própria paisagem. É algo que the é atribuído a partir de construções humanas pautadas em consensos e acordos. Assim, a paisagem é considerada segundo as variáveis tempo e espaço, simultaneamente. (CONNOR, 1994). Sob essa ótica, pode-se afirmar que a noção de valor é relativa e intersubjetiva, o que the concede múltiplos conteúdos e interpretações, variando de cultura para cultura e de lugar para lugar.

Fica compreendido que a paisagem é um bem natural e cultural, que pode ser analisada levando-se em consideração o processo histórico de suas apropriações e evocações, as quais são histórica e geograficamente específicas.

Nessa perspectiva, serão tratados alguns recortes físico-espaciais da cidade, tanto para a análise da paisagem do rio Capibaribe como a do Manguezal do Pina. Buscaremos a interpretação e a identificação dos valores a eles atribuídos por aqueles que habitam nas suas margens, assim como pelos envolvidos na sua (trans)formação. Os valores serão interpretados a partir das relações socioculturais estabelecidas com esses recursos naturais, tendo como pressuposto o conteúdo da relação entre os grupos humanos e a paisagem com a qual interagem ou vivenciam.

Nesse sentido, questiona-se em que medida os valores atribuídos às paisagens do rio Capibaribe e aos Manguezais do Pina estão relacionados aos contextos socioeconômicos e culturais daqueles que as representam? São valores consensuais ou existem contradições entre os mesmos? Essas questões nortearão o desenvolvimento do texto exposto.

Assim, visando à identificação dos valores atribuídos a uma fração da paisagem do rio Capibaribe e do Manguezal do Pina, este texto será estruturado em duas partes: na primeira, será tratado o contexto natural e cultural que norteou a formação destas paisagens, a partir das relações culturais estabelecidas entre os agrupamentos humanos e esses elementos naturais, e, na segunda, serão interpretados os significados e representações sociais com base nos valores atribuídos às paisagens desses bens naturais e culturais por agrupamentos humanos que os vivenciam de forma direta ou indireta.

\section{A PAISAGEM DOS RIOS E MANGUEZAIS DO RECIFE}

Os rios e os manguezais da cidade do Recife muito contribuíram com o processo de formação e estruturação do seu sítio urbano. Isso foi originado desde a fundação da cidade, que se deu a partir do porto cujo desenvolvimento como atividade econômica durante o século XVII só foi possível em virtude da produção de açúcar pelos 
engenhos estabelecidos nas "[...] várzeas do baixo Capibaribe e do baixo Beberibe, [...] de excelentes solos de cana e situada à pequena distância do nódulo da colonização". (MELO, 1978).

Esse contexto resultou no tipo de economia e sociedade existentes naquele período. O rio Capibaribe contribuiu como suporte para as atividades econômicas e também utilitárias, pois era utilizado para o escoamento do açúcar, para o transporte dos moradores dos engenhos e dos núcleos de povoação, assim como servia de fonte de abastecimento d'água. Devido ao valor utilitário, estabeleceu-se uma relação entre moradores ribeirinhos, rio e manguezais, que se expressa nos valores atribuídos a esses sistemas naturais.

A cidade do Recife foi construída sobre ilhas e terras ladeadas por áreas alagadiças, conquistadas aos rios e aos pântanos. (MELO, 1978). Teve o traçado urbano condicionado pelo seu sítio fluvial e deltaico, resultando no atual perfil da cidade. Segundo o arquiteto historiador José Luís Mota Menezes', "O rio Capibaribe desenha a cidade do Recife, o que sobrou do rio é que é a cidade, que muitas vezes roubou do rio solo firme". Oliveira (1942, p. 38-39) também afirmou:

[...] no Recife, o que não é água, foi água ou lembra a água [...] água do mar que cobriu em época remotíssima, água dos rios que a cortam e recortam [...] água subterrânea [...] água dos pântanos que a vegetação dos mangues ensombra e oculta, água do mar que não capitula deante dos recifes e volta, duas vezes por dia, a visitar, pelos braços dos rios, os seus domínios perdidos.

Assim, as águas e os manguezais são elementos naturais que sempre marcaram a fisiografia da cidade do Recife. Sendo resultado de um trabalho de acumulação sedimentar em uma antiga baía, Castro (1966, p. 168-169), tratando o Recife como uma enseada, afirmou: "O aterro ou enchimento da enseada se fez sob a ação conexa e sucessiva de variados fatores, entre os quais se destacaram os rios, o mar, o vento e a vegetação dos mangues, fixadoras de detritos e consolidadora dos solos."

Além dos fenômenos geofísicos, como a regressão marinha, provocando a substituição dos manguezais, outros fatores, como a ação antrópica, culminaram na transformação radical do facies aquoso da cidade, contribuindo para o desaparecimento de grande parte do ecossistema manguezal. $\bigcirc$ uso e a ocupação das áreas de manguezais, de forma paulatina, ao longo do período de construção da cidade, caracterizaram o processo de colonização que perdurou por séculos, apresentando-se hoje com drásticas consequências. (BEZERRA, 2000).

A urbanização intensiva alterou a dinâmica do sistema natural da cidade, comprometendo a integridade das águas e dos manguezais. A quebra do equilíbrio dos ecossistemas aquáticos provocou o comprometimento do ciclo dos nutrientes, causando desaparecimento de espécies e, consequentemente, afetando a produtividade pesqueira e a degradação do solo. Isso foi consequência das drásticas formas de desmatamento

Em entrevista concedida a Vera Lúcia Mayrinck de Oliveira Melo (maio de 2001). 
para utilização do mangue como combustível, para obtenção de madeira para construção civil (estacas, cercas, molhes, paliçadas) ou mesmo barcos e artefatos artesanais de pesca. Entretanto, o acelerado processo de urbanização consolidou o aterro sobre rios e manguezais como prática usual e forma específica de criação de solo para ampliação do espaço urbano construído. (BEZERRA, 2000).

Assim, desde sua gênese, as históricas paisagens do Recife representadas pelo rio Capibaribe e pelos manguezais, devido ao processo de aterro das várzeas e dos mangues - visando à ampliação da terra firme -, passaram por processos de mutação decorrentes das práticas humanas sobre a morfologia desses bens naturais. Observa-se o estabelecimento de uma relação em que há predomínio da ação humana sobre as condições naturais. Relação entendida a partir dos valores atribuídos à natureza por aqueles que a modificam em benefício de interesses específicos.

Durante todo o processo de desenvolvimento da cidade, ao ser tratado como receptor de dejetos devido à inexistência de sistemas de esgotamento sanitário, fica explícita a degradação do rio Capibaribe. O setor público não tem investido na melhoria desses sistemas, nem em melhorias da qualidade das águas da cidade. Apenas cerca de 33\% da área da cidade de Recife é saneada, relevando-se o fato de que as indústrias também promovem a polvição das águas, registro que remonta o final do século XIX, com a implantação das usinas de açúcar.

Outro fator que contribuiu para o processo de degradação do rio Capibaribe foi a ampliação e intensificação da ocupação das suas margens, que teve início no fim do século XIX, com o processo de migração no sentido campo-cidade. A população migrante, sem condições de acesso a terras urbanas, foi se instalando nas áreas de mangues e alagados, terras menos valorizadas, construindo ali seus mocambos, utilizando-se da pesca como meio de subsistência. (CASTRO, 1966). Para Castro (1966, p. 219): “O Recife, cidade dos rios, das pontes e das antigas residências palacianas - é também a cidade dos mocambos - das choças, casebres de barro batido a sopapo, com telhados de capim, de palha, e de folhas de Flandres."

O quadro de degradação que apresenta o rio Capibaribe tem sido alvo de denúncias na imprensa periódica e em outras publicações literárias desde 1847. Apesar desse quadro caótico, o rio Capibaribe, bem como as pontes localizadas no centro da cidade do Recife, foi escolhido pela população recifense como o símbolo mais representativo da cidade, em pesquisa realizada em 1997. (CHACON, 1959). Esse resultado ratifica a importância desse elemento hídrico para a cidade do Recife, pois a "História do Capibaribe é a História do Recife."

Por outro lado, a referência histórica dos manguezais para a cidade do Recife é de suma importância. Bezerra (2000) enfatiza que, a despeito da significativa redução de massa vegetal de mangues e áreas estuarinas, a paisagem da cidade está associada à imagem das águas e manguezais. Representam marcas singulares com importante valor histórico-cultural.

Atualmente, os manguezais ainda subsistem e se fazem presentes na morfologia urbana da cidade, apesar do avassalador processo de urbanização tê-los quase sub- 
traídos em sua totalidade. São fortes referências como elementos do sítio geográfico, bem como permeiam as representações socioculturais do povo, apreendidas a partir da interpretação da relação peculiar estabelecida entre recifense/manguezal.

Compreendendo esse contexto, parte-se do pressuposto que o significado dos rios e manguezais para os recifenses está relacionado às vivências estabelecidas entre eles. O conteúdo dessas relações pode ser captado a partir das representações reveladas em discursos, falas e expressões orais. Partindo dessa abordagem, é possível avaliar a importância e o significado dos valores atribuídos ao rios e manguezais do Recife.

Contudo, pode-se constatar a contradição existente entre os grupos humanos analisados observando os distintos valores atribuídos à paisagem do rio Capibaribe e do Manguezal do Pina, considerando a relação entre os grupos e esses recursos naturais. Como os grupos não são homogêneos, nem as paisagens possam ser consideradas neutras ou estáticas, visto que refletem diversos conteúdos em cada contexto sociocultural e histórico-geográfico, as paisagens do rio Capibaribe e do Manguezal do Pina inserem significados pautados em referenciais de valores distintos. Muitas vezes apresentam-se conflitantes, pois a forma de olhar a paisagem é cultural, e a cultura não está presente da "mesma maneira em todos os representantes de uma sociedade".

\section{OS SIGNIFICADOS DE UM RECORTE DA PAISAGEM DO RIO CAPIBARIBE}

A interpretação dos significados da paisagem teve como base, por um lado, os valores atribuídos ao rio Capibaribe pelos grupos que habitam o recorte espacial, formado pelos bairros do Poço da Panela, Monteiro, Apipucos, Iputinga e Cordeiro (zona oeste da cidade); por outro, por aqueles que estão envolvidos na confecção das paisagens.

Neste segundo recorte se incluem os planejadores urbanos, os ambientalistas e os representantes do setor imobiliário, cuja análise se baseou em dados qualitativos, tendo como procedimento a entrevista semiestruturada. Os depoimentos orais foram considerados como uma série de construções culturais, cada uma representando uma visão particular de mundo.

Os significados dessas paisagens se diferenciam entre os grupos culturais de acordo com o tipo de uso que fazem do rio e pela maneira de se relacionar com o mesmo como também pelo o nível socioeconômico e pela formação sociocultural dos diferentes grupos sociais baseadas em valores e interesses distintos. Para Cosgrove (1998), as diferentes posições ocupadas pelos grupos culturais na sociedade resultam em consciências e experiências distintas e a evidência dessas diferenças se expressa na paisagem. Para apreender os significados que o rio Capibaribe possui para os diferentes grupos culturais, foram destacados elementos enfatizados nas entrevistas para expressar os valores atribuídos à paisagem.

2 Editorial do periódico Géographie et Culture n 1, 1992, p. 4-5. 
O valor mais ressaltado pelos moradores ribeirinhos de classe de baixa renda foi o rio como fonte de sobrevivência, pois este é, dentre os grupos culturais, o único que tem alguns membros dependendo do rio para sobreviver - apesar da redução cada vez maior do número de pescadores devido à poluição existente. Outro grupo que também destacou esse valor foi o dos representantes dos órgãos públicos, no entanto, relacionando a fonte de sobrevivência à vida "porque a água é alimento".

O segundo valor do rio Capibaribe mais mencionado por esses moradores foi o estético. Apesar de os habitantes inseridos nesse grupo morarem nas margens do rio, por não terem outra alternativa, e muitos se mostrarem insatisfeitos pela precariedade das condições ambientais nas quais vivem, valorizam a beleza natural do rio. Os significados do rio, expressos através do valor atribuído apenas por esse grupo cultural foram o perigo e a natureza. $O$ primeiro significado é decorrente da proximidade do rio em relação ao grupo, que vive no dia a dia a sua intimidade e, por isso, muitas vezes sente a ameaça das cheias e da violência exposta - não raro por corpos mortos boiando nas águas.

O segundo significado mostra que alguns membros desse grupo cultural ainda conseguem perceber no rio valores associados à natureza, mas ele também significa para esse grupo tranquilidade e símbolo de vida, assim como para os moradores ribeirinhos de classe de renda alta, que, apesar de estarem próximos do rio, são apenas observadores do mesmo. A água que flui, mesmo polvída, transmite paz e estado de harmonia, que para esses grupos sociais se relaciona à vida e à fonte de alimentação, o que demonstra como são contraditórios os significados do Capibaribe, baseados em valores relacionados às sensações de medo, de tranquilidade, de rejeição à polvição e de admiração. (MELO, 2003).

O significado do rio mais ressaltado pelos moradores ribeirinhos de classe de renda alta foi o valor estético, vinculado à contemplação e experienciação da beleza natural. Para esse grupo, o valor contemplativo atribuído tão fortemente ao rio está relacionado ao fato de não vivenciarem os problemas das condições ambientais emergentes, pois moram de costas para o rio ou o observam do alto de suas casas. (MELO, 2003).

Cabe destacar que o significado do rio vinculado ao valor estético foi um dos mais mencionados pelos especialistas em planejamento urbano e representantes dos órgãos públicos. Esse significado, para o primeiro grupo de observadores, formado por aqueles que o analisam técnico-cientificamente, foi o mesmo relatado pelos moradores ribeirinhos. No entanto, para o segundo grupo teve conotação diferente, pois alguns daqueles que têm como práxis intervir na paisagem vincularam o significado do rio à formação das paisagens do Recife, como se pode destacar no depoimento: "Significa um elemento que definiu e estruturou uma paisagem, pois, mesmo fluindo continuamente, congelou no tempo registros de uma ocupação [...] quando era utilizado como eixo de penetração [...] significativo para a história de construção da cidade."

Outro significado destacado pelos grupos culturais investigados foi o valor do rio como símbolo de vida, expresso de várias formas. Os moradores ribeirinhos se referiram ao rio como a um ser vivo e a uma fonte de alimentação - enquanto para os 
outros grupos o valor representou símbolo de vida, tendo em vista a importância dos aspectos bioecológicos.

Nesse sentido, os especialistas em planejamento urbano e ambiental ressaltaram os valores biológicos e geofísicos, e aqueles que vincularam o significado ao valor da vida, através das suas potencialidades ecossistêmicas, foram os representantes do setor público e os ambientalistas. Este último grupo foi o que mais mencionou o valor da vida em relação ao rio, demonstrando a influência de sua prática profissional na significação do rio.

Os ambientalistas foram o único grupo cujos membros relacionaram o significado do rio Capibaribe à polvição. Tal fato decorre de sua atividade profissional estar relacionada às questões ambientais, e assim demonstram o confronto entre a polvição, significando a morte lenta do rio, e o seu significado como símbolo de vida. Alguns expressaram que "o rio significa um ser vivo que está doente"3; "...] traz a vida, leva e traz as pessoas, as esperanças [...] e também é um mensageiro de más notícias". ${ }^{4}$

O significado pautado no rio Capibaribe como símbolo da cidade do Recife foi manifestado pelos representantes de classe de renda alta e pela maioria dos outros grupos culturais. Para os representantes do setor imobiliário, o rio Capibaribe significa o principal marco da cidade, o monumento e a identidade do Recife. Por esse prisma, pode-se questionar se o valor simbólico não agrega valor econômico aos imóveis que estão inseridos nas margens do rio, principalmente, aos altos edifícios, de onde se contempla a sua paisagem.

Os especialistas em planejamento e os ambientalistas se reportaram ao rio Capibaribe como uma referência da paisagem urbana e como elemento de maior valor afetivo da cidade. Conforme expresso por uma parte dos moradores ribeirinhos e pelos outros grupos culturais, bem como para a maioria da população recifense que o escolheu (através de uma pesquisa), o rio Capibaribe pode ser considerado, simbolicamente, o marco mais significativo da cidade do Recife.

Assim, observou-se que os significados do rio Capibaribe pautados nos valores e interesses dos grupos culturais são múltiplos, seja para os que vivenciam o rio no cotidiano, para os que estão mais próximos e têm intimidade com o mesmo e para aqueles que ocupam as suas margens, mas mantêm distância por se encontrarem de costas para o rio ou por morarem nos altos edifícios ribeirinhos.

Tais significados também se diferenciam entre aqueles que fazem parte de um mesmo grupo cultural e que desempenham as mesmas atividades profissionais. Houve os que expressaram o significado do rio de forma mais objetiva e outros que ressaltaram aspectos subjetivos, ligados ao sentimento e à emoção que esse elemento hídrico Ihes transmite. Outros grupos, alguns profissionais, demonstraram como a formação

\footnotetext{
3 M. M., médico e ambientalista, membro da Sociedade Nordestina de Ecologia (SNE), conselheiro do Conselho Municipal do Meio Ambiente (COMAM. ).

4 A. A., ecologista, presidente da Associação Pernambucana de Defesa da Natureza (ASPAN).
} 
intelectual direcionada por conceitos pré-determinados influenciou no significado que o rio possui para eles.

Assim, a análise e interpretação de distintas camadas superpostas de significados ajudaram a apreender a heterogeneidade dos valores das paisagens do rio Capibaribe.

\section{OS VALORES DA PAISAGEM DOS MANGUEZAIS OS SIGNIFICADOS DO MANGUEZAL DO PINA}

Conhecida a evolução histórica da formação do sítio urbano da cidade do Recife, como já descrito e enfatizado, pode-se afirmar que as águas e os manguezais são os elementos naturais que sempre marcaram a fisiografia e a história da construção urbana do Recife. Para Bezerra (2000), grande parte de seu sítio urbano foi e ainda é submetido a inundações e enchentes, ora pelas águas do mar, ora pelas águas dos rios, ou simultaneamente, o que the confere caráter aquoso. Daí a morfologia de sua paisagem estar sempre relacionada aos rios ou aos manguezais.

Sob o prisma da abordagem teórica das representações sociais, a análise e a interpretação dos valores atribuídos à paisagem dos manguezais do Recife, segundo esta investigação, foi analisada por Bezerra (2000) a partir de diversos olhares - moradores ribeirinhos de baixa renda e de classe média alta; especialistas, ambientalistas e gestores públicos. Buscando identificar os valores atribuídos à paisagem, a investigação enfocou o conteúdo da relação entre citadinos recifenses e os manguezais da cidade, especificamente o Manguezal do Pina.

Partindo das vivências e experiências estabelecidas ou construídas pelos grupos humanos em relação a esse recurso natural, verificou-se em que medida a valorização dos manguezais ocorrem e quais os fatores que influenciam na relação homem/natureza. Enfatizaram-se os elementos naturais como recurso utilitário, fruição da beleza natural ou contemplação paisagística e o sentimento de identidade e afetividade desenvolvido em relação ao meio vivenciado.

A análise se processou mediante a aplicação de entrevistas e questionários aos grupos humanos em foco, captando os conteúdos que subjazem aos discursos e às falas das pessoas investigadas. Levando em conta a relação dos grupos tratados e sua relação, direta ou indireta, com os manguezais, identificaram-se distintos valores atribuídos a esses bens naturais, cujo conteúdo variam de acordo com o contexto da relação estabelecida entre eles.

Para os moradores ribeirinhos de baixa renda, que vivem da pesca e dos produtos fornecidos pelo ecossistema manguezal, o destaque maior foi para o valor utilitário, em face do usufruto da oferta econômica e alimentar a eles proporcionados. $\bigcirc$ manguezal foi representado como fonte de alimento e sobrevivência física e material. Por outro lado, também aflorou o valor afetivo e de identidade, posto que o grupo mantém com aquele meio uma relação simbiótica de vida e subsistência que permite emergir o sentimento identitário com o lugar. 
Esses valores se complementam com o sentimento de admiração e contemplação da paisagem revelado pelo valor cênico ou beleza natural, resultado da experienciação estética que se processa entre sujeito e objeto. Segundo Bezerra (2011), o valor da beleza natural ou cênica pode ser compreendido no âmbito filosófico da estética, que corresponde à experiência estética humana diante dos objetos, aflorada quando na presença da beleza de um deles, visto que a beleza, conforme pontua Duarte Jr. (2009, p. 192), não se encontra "[...] nem no objeto em si, nem isoladamente nos sujeitos humanos".

Pelos moradores ribeirinhos de classe média alta, o valor destacado foi o contemplativo ou da beleza natural, relacionando-se, portanto, ao aspecto físico-visual. Apesar da proximidade da moradia com o manguezal, foi registrada uma rejeição quanto ao "elemento mangue", em face desse ambiente historicamente estar relacionado com a ocupação e a tomada de terras baixas e alagadas pelo estrato social de menor poder aquisitivo da cidade. Esse aspecto associou o manguezal à pobreza e às áreas de menor valor imobiliário, sendo, simbolicamente, representado por "lama" ou "alagado". Esse grupo social não faz do Manguezal do Pina um elemento referencial de lugar, e sim a faixa de praia ou a orla de Boa Viagem. Embora esta fique mais distante de suas moradias, é o elemento natural mais valorizado da cidade e do bairro, especialmente.

O grupo representado pelos especialistas e estudiosos, devido à relação "distante" do objeto e por serem portadores de um filtro técnico e científico, apreendem o manguezal como um bem natural e uma estrutura ambiental e geofísica da cidade. Também enfatizam o manguezal como elemento histórico-cultural da paisagem urbana. Valorizam-no como marco cultural singular da paisagem recifense, sobretudo como recurso natural importante para o ecossistema pela função bioecológica, pelos serviços e benefícios que presta à população, principalmente enquanto processo produtivo alimentar e de sobrevivência humana.

Destacaram ainda o valor da exuberância da massa vegetal que representa através da funções de equilíbrio dos ciclos climáticos e hidrológicos, proporcionando amenização do clima e amortecimento de enchentes. Teve destaque o valor estético da paisagem por tratar-se de elemento cênico de beleza natural singular, que pode ser usufruído como recurso de apreciação visual, lazer e recreação.

Similarmente a esse grupo, os ambientalistas também avaliaram o manguezal pelos mesmos critérios técnico-científicos, dado ao conhecimento desenvolvido acerca do valor físico-biológico desse elemento natural. Contudo, diferenciaram-se dos critérios dos especialistas e estudiosos em face do forte engajamento político à causa socioambiental, defendendo-a ferreamente como bandeira a ser empunhada pela sociedade, cujo objetivo visa à manutenção e à proteção dos valores da natureza e da vida no planeta.

Por último, o poder público apresentou em seu discurso, na ocasião da pesquisa, o valor de uso da natureza, empregado em prol do desenvolvimento urbano da cidade. Apresenta, portanto, teor utilitarista e economicista ao analisar o espaço urbano como locus de reprodução do capital econômico. 
A ideia de natureza transmitida pelos órgãos institucionais está eivada de vícios político-econômicos ao compreender o ambiente natural como parte integrante da engrenagem econômica à qual todos se subordinam e dela dependem para a sobrevivência material humana. Nas entrelinhas dos discursos e falas, foi apreendido que o ambiente, seja natural ou cultural, existe para a sobrevivência humana, sendo esta determinada pelo setor econômico.

Portanto, o valor atribuído ao manguezal por esse grupo está relacionado a ideia de recurso natural a ser usufruído pelo homem para o seu desenvolvimento físico-material. Pode-se afirmar que aí reside um forte teor antropocêntrico, milenarmente construído, que ainda subsiste fortemente nas entranhas e nas estruturas institucionais construídas pelo homem, revelando-se nas ações e políticas de planejamento, planos e projetos e urbanísticos.

\section{CONSIDERAÇÕES FINAIS}

A interpretação dos depoimentos orais dos grupos humanos revelou a diversidade de significados que as paisagens dos rios e manguezais do Recife revelam a partir dos valores atribuídos a esses elementos ou bens naturais da cidade. Os registros identificados expressaram os interesses dos grupos culturais, mobilizados pela defesa dos seus valores no momento da construção das paisagens. Isto ocorre porque se entende que o olhar sobre a paisagem daqueles que a vivenciam no cotidiano e o dos que a observam se baseiam em crenças, valores e interesses distintos.

Compreendendo que a confecção das paisagens resulta de várias expressões culturais, deve-se considerar essa diversidade quando da construção dos instrumentos políticos de planejamento e de gestão dos processos de conservação patrimonial das mesmas.

A paisagem como patrimônio, em sua ampla acepção de natural e cultural, pode ser compreendida como objeto de conservação cujo foco de proteção é sua significância ${ }^{5} \mathrm{e}$ seus conjuntos de valores, materiais e imateriais, que the são atribuídos e reconhecidos intersubjetivamente pelos grupos humanos que com ela interagem.

Essa perspectiva abre uma trilha para o desenvolvimento de uma abordagem teórico-metodológica pela qual seja possível caminhar através de meandros que envolvam a relação entre os grupos humanos e o seu meio natural, partindo da apreensão das subjetividades e vivências expressas nas representações socioculturais.

Entende-se, assim, que a relação que se estabelece entre homem e natureza, captada por meio do mundo vivido, através de representações ou evocações humanas, traduz o conteúdo dessa interação, demonstrada pelos valores atribuídos ao ambiente vivido,

5 Os valores patrimoniais têm seu conceito baseado nas orientações e diretrizes estabelecidas nas cartas patrimoniais da significância natural contidas na Carta do Patrimônio Natural (Australia Natural Heritage Charter, UNESCO, 1996), que a define como sendo a importância dos ecosssistemas, a biodiversidade e a geodiversidade pelo seu valor de existência, ou em termos dos valores científico, social, estético, e como suporte de vida das presentes e futuras gerações; e a significância cultural é definida pela Burra Charter (UNESCO, 1999) como o conjunto de valores estéticos, históricos, científicos ou sociais de um bem para as gerações passadas, presentes e futuras. 
de forma subjetiva e intersubjetivamente reconhecida. Daí a possibilidade de analisar a paisagem enquanto bem natural e cultural dentro de uma abordagem que considere suas dimensões materiais e imateriais, e que possa servir de orientação metodológica norteadora do desenvolvimento de instrumentos e ações aplicados ao processo de gestão da conservação integrada do bem patrimonial.

\section{REFERÊNCIAS BIBLIOGRÁFICAS}

BEZERRA, Onilda Gomes. O Manguezal do Pina: a representação sociocultural de uma paisagem. 2000. 337 f. Dissertação (Mestrado em Geografia Humana) - Departamento de Ciências Geográficas da Universidade Federal de Pernambuco, Recife, 2000.

A conservação do patrimônio natural/cultural: um sistema de indicadores para o monitoramento

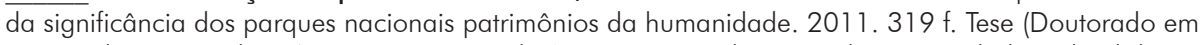
Desenvolvimento Urbano) - Departamento de Arquitetura e Urbanismo da Universidade Federal de Pernambuco, Recife, 2011.

CASTRO, Josué de. Um ensaio de Geografia Urbana: a cidade do Recife. In: Ensaios de Geografia Humana, Parte II. São Paulo: Brasiliense, 1966, p. 155-226.

CHACON, Vamireh. O Capibaribe e o Recife: história social e sentimental de um rio. Recife: Secretaria de Educação e Cultura de Pernambuco, 1959. 138 p.

CONNOR, Steven. Teoria e valor cultural. São Paulo: Edições Loyola, 1994. 276 p.

COSGROVE, Denys. A geografia está em toda parte: cultura e simbolismo nas paisagens humanas. In: CORREAA, Roberto Lobato et al. (Org.). Paisagem, tempo e cultura. Rio de Janeiro: EdUERJ, 1998, p. 92-123.

DUARTE Jr., João Francisco. O que é beleza. São Paulo: Brasiliense, 2009. 94 p.

MELO, Vera Lúcia Mayrinck de Oliveira. Um recorte da paisagem do rio Capibaribe: seus significados e representações. 2003. 273 f. Tese (Doutorado em Geografia Humana) - Faculdade de Ciências Geográficas da Universidade do Rio de Janeiro, Rio de Janeiro, 2003.

MELO, Mário Lacerda de. Metropolização e subdesenvolvimento: o caso do Recife. UFPE, Centro de Filosofia e Ciências Humanas, Departamento de Ciências Geográficas, 1978. 256 p.

OLIVEIRA, Waldemar de. Geologia da planície do Recife: contribuição ao seu estudo. Tese de concurso à cátedra de História Natural da Escola Normal Oficial de Pernambuco. Recife: Oficinas Gráficas do Jornal do Comércio. 1942.

PONTES, Carlos Antonio Alves. Urbe água vida: ética da proteção aplicada ao estudo das implicações morais no acesso desigual à água potável. 2003. 283 f. Tese (Doutorado em Saúde Pública) - Escola Nacional de Saúde Pública/Fundação Oswaldo Cruz, Rio de Janeiro, 2003.

SANTOS, Milton. A redescoberta da natureza. Estudos Avançados. São Paulo: Edusp, v. 6, n. 14, janeiro-abril, 1992, p. 95-106.

SILVA, Elmo Rodrigues da. O curso da água na história: simbologia, moralidade e a gestão de recursos hídricos. 1998. 190 f. Tese (Doutorado em Saúde Pública) - Escola Nacional de Saúde Pública/Fundação Oswaldo Cruz, Rio de Janeiro, 1998. 